\title{
The Management Thoughts Of Salt Merchants Jiang Chun
}

\author{
Han songai $^{1, a}$, Xiao xingzheng ${ }^{2, b}$ \\ 1. 2Sichuan University of Science \& Engneering,Zigong,china \\ $\underline{a x x z 125 @ a l i y u n . c o m}$ \\ b1714749418@QQ.com)
}

Corresponding author:xiao xingzheng

\begin{abstract}
During the Ming and qing dynasties, because of "Ye Qi Reform" making the rise of the liang huai salt merchants, jiang chun, a anhui merchant, was the typical representative of this period. The process of the rise and fall in liang huai salt industry, contained many management thoughts. Great salt merchants jiang chun 's stories for "Confucian merchant" and the characteristics of the integrity of righteousness, had a big effect on the prosperity of the salt industry . Moreover, he befriended dignitaries as their agents, so as to maintain their own political status, which would be obtaining economic benefits; he made friends with scholar and undertook social responsibility, which had played a very good effect on positive publicity; he also attached great importance to the education of ethnic, and realized the sustainable development of salt industry. All in all, the management thoughts of jiang chun had a certain practical significance on the modern management.
\end{abstract}

Key words: salt merchants jiang chun, management thoughts, the practical significance

\section{盐商江春的经营管理思想初探}

\author{
韩松爱 $^{1, a}$, 肖兴政 ${ }^{2, b}$ \\ 1.2. 四川理工学院 中国, 自贡 \\ axxz125@aliyun.com \\ b1714749418@QQ.com \\ 通讯作者: 肖兴政
}

中文摘要：明清时期，由于 “叶淇变法”， 使两淮盐商兴起，徽商江春是这个时期典型 的代表。在两淮盐业兴衰的过程中，蕴含着 江春丰富的管理思想。大盐商江春因 “儒 贾”而诚信仁义的特点，对整个盐业的兴盛 有很大的关系。不仅如此，他结交权贵，维 护自己的政治地位，获得经济利益; 以文会
友和承担社会责任, 更是对自己正面的宣传 起到了很好的效果; 他还非常注重族人的教 育, 实现盐业的可持续发展。总之, 研究江 春的经营管理思想对现代管理者具有一定的 现实意义。

关键字：盐商江春，管理思想，现实意义 


\section{1. 引言}

明清时期, 徽商盐商的兴盛与衰败, 向 世人展示了一个群体的时代样本, 曾经雄据 一方, 傲视群雄数百年, 对我国封建社会后 期商品经济的发展、市场的扩大, 起到了很 大的作用。其中以乾隆年间担任总商四十余 年, “以布衣上交天子” 的江春最为有名。在 两淮盐业史上, 江春是一位纵横牌圔, 叱咤 风云的人物。他为清朝廷效尽了犬马之劳, 成为清乾隆朝显赫一时的盐商代表。这位最 牛徽商 “一夜造白塔” 的故事广为人知, “四 大徽班进京” 也与他有莫大的关系。从他的 身上, 处处都凝聚着其杰出的管理思想, 比 如说 “儒贾” 讲究诚信, 利与义的取舍; 结 交官僚, 为自己维护政治地位; 对后代的教 育, 实现可持续发展; 以文会友, 对自己进 一步宣传; 承担社会责任, 实现自己的使命 等。遗憾的是, 虽然几经腾挪辗转, 也未能 摆脱盐商 “盛极而衰” 的宿命。

\section{2. 江春与盐业的关系}

明清时期, 盐政与河工、漕运同被视为 事关国计民生的要政。在徽州盐商兴起之前, 经营盐业的主要商帮是晋商。山西作为朱元 璋时期实施“开中制”盐业政策的“试验田”, 晋商几乎垄断了当时的整个盐业市场, 这种 局面直到一场盐业变革之后才有所改观。

1492 年，明朝户部尚书叶淇在其上任后 的第二年发动了一场盐法变革, 史称 “叶淇 变法”, 即变 “开中制” 为 “开中折色”。“叶 淇变法” 不仅使山西盐商失去了 “开中制” 带给他们的地域之便, 也在有意无意之间推 动了徽州盐商的崛起。徽州盐商紧抓时机、 以扭转逆势的魄力终于打破了徽商在盐业上 停滞不前的局面。

“叶淇变法”后, 两淮盐运司设在扬州, 两浙盐运司设在杭州, 这两处都离徽州很近。 凭借显著的地理优势和高收益, 成批的徽商 投入到了盐业经营行列。由于两淮盐场盐质 好, 盐利高, 所以徽商又主要集中在扬州。 徽商几乎占据扬州的盐业市场, 而从事盐业 的高额利润也使不少徽商很快致富。
江氏家族在此抓住契机, 江春的祖父与 其父江国茂 “担囊至扬州” “用才智理盐策”, “数年积小而高大”, 成为两淮盐商的中坚人 物, 为江氏家族在盐业的发展起了抛砖引玉 的作用, 经过祖辈的努力, 江氏家族所掌握 的盐引数占了两淮盐引总数的十分之一。

江春, 字颖长, 号鹤亭、广达, 徽州撮 县江村人, 因出身盐业世家, 之后继承祖业, 为清乾隆时期 “两淮八大总商”之首, 又因 其 “一夜堆盐造白塔, 徽菜接驾宴乾隆” 的 奇迹，而被誉作 “以布衣结交天子” 的 “天 下最牛的徽商”。据《扬州画舫录》所记, 江春任总商四十年, 先后蒙乾隆赏赐 “内务 府奉宸苑卿”、“布政使” 等头衔, 荐至一品, 并赏戴孔雀翎, 为当时盐商仅有的一枝, 时 谓江春 “以布衣上交天子”，“同业中无不以 为至荣焉”。

江春少年时曾立志读书取功名, 他曾拜 当时名士太史王已山为师, 埋头苦读。乾隆 六年 (1741 年), 江春 “以五经应试未第, 遂出其才治㕹业” ${ }^{[2]}$ 。就此, 他放弃了通过 科举考试做官的道路, 跟随父亲江承瑜悉心 经营盐业。

乾隆十四年 (1749), 江春因其 “练达多 能, 熟悉盐法”, 他的才能很快就受到了盐业 同行的推崇, 并且深得两淮盐运使的倚重, 遂被推举为两淮盐区总商。担任总商之后, 江春不仅 “每发一言定一计, 群商张目拱手, 画诺而已” ${ }^{[3]}$, 而且官府也 “凡重事皆与擘 画” ${ }^{[4]}$ ，因此担任该职四十余年。从此，江 春成了 “一身系两淮兴衰” 的盐业巨头。

世袭制度及近乎垄断的地位, 迅速让徽 州盐商在三大盐商中脱颖而出, 也为之后徽 州盐商称霸两淮添上了重墨重彩的一笔, 而 江春也自然而然成为两淮盐商的典型代表。

在经营活动中，徽商江春不仅秉承了儒 家的信条, 而且他在经营盐业的过程中, 体 现了杰出的经营手段与管理思想, 给现代管 理者以启示, 为后人所称赞。

\section{3. 江春的经营管理思想}

\section{1 贾而好儒, 创立 “企业文化”}

儒学是中国封建社会中居统治地位的主 流文化, 也是 “徽文化” 的根基。徽商的最 
主要特征就是 “儒贾”, 他们以儒学为指导思 想, 形成了共同的观念、信仰、伦理道德、 礼仪风俗的文化特质, 建立了一种为同行所 公认、自愿遵守的诚信仁义商业行为规范和 商业文化模式。

\section{1.1 贾而好儒，士商结合}

在徽州流传着一句俗语: “三代不读书, 不如一窝猪”。“贾而好儒” 是徽商的显著特 点, 这就对徽商产生两方面的影响。首先, 徽商由于 “好儒”, 从而整体文化素质较高, 较高的文化素质又成为他们与官僚士大夫交 往的 “粘合剂”, 同时也给徽商的商业经营带 来了许多便利。之后他们经过长期的经营活 动中, 再加上受到当时的经济、政治和社会 环境的影响, 还有他们大多从小就秉受传统 文化教育与滋润, 因而形成了比较完整的而 且能体现 “儒贾” 的经营特色。

3. 1.2 以儒道经商, 诚信为本

自幼接受经史文化考卷、儒家道德熏陶 的盐商, 受儒家思想潜移默化的影响, 往往 能自觉地运用儒道经商, 用儒家的价值取向 和伦理道德作为标准, 从而规范自己的商业 行为, 即所谓的 “贾服而儒行”、“每引经义 自断”、“一以书生之道行之” 等, 也就是用 儒家思想作为自己经商的指导思想, 以儒家 的仁、义、忠、信核心理念来经商理财, 诚 信为本, 以义取利, 以智取胜。

江春的身上就兼具 “儒贾” 的特点, 即 既具有儒家思想, 又具备了新的经营商品经 济的经济头脑。“儒” 是为了 “名望”, “贾” 为了 “厚利”, 两者又可以相互为用, “人毕 事儒不效, 则弛儒而张贾; 既侧身飨其利矣, 及为子孙计, 宁弛贾而张儒。一张一弛, 迭 相为用, 不万钟则千驰, 犹之转毅相巡, 岂 其单厚计然手哉, 择术审矣。” 江春, 就是这 样, 在这一张一弛之间, 经营着自己的盐业。 ${ }^{[8]}$ 在之后的商业经营中, 江春就表现出儒商 的风度, 亦即为人们所评述的: “询询雅饰, 贾而儒者也。”还有很多像江春这样的“儒商” 如休商汪坦, 虽托游于货利之场, 然非义弗 取。“其遇物也咸取其直而济之以文雅”。他 不仅不牟暴利, 而且待人谦和。款商张景文 出身于“文学之家”, 后来“更修卓郑业经商”, 在商场中, “然终以儒贾不肯事握醒琐屑, 较 计针株”。 ${ }^{[9]}$ 这是一般钻营小利的刀猾之辈无
可比拟的。

\section{1.3 利而思义, 多行义举}

在封建社会, 忠君爱国是儒家道德理论 规范的重要内容。服膺儒术、奉行儒道的两 淮盐商在集聚巨额资本后, 对清廷表现出巨 大的报效热忱。江春就是其中一个，他把儒 家思想转化为实际行动, 用儒家思想指导经 商实践, 本着 “儒道” 经商, 不设智巧, 不 图小利, 其结果, 往往竟能获得大利。正因 为这样而“家业隆起”、“丰亨豫大”, 甚至 “坍 素封矣”。何以如此呢? 中国的儒家学说, 历 来主张“义利双行”, 并非只讲“义”不讲“利”。 但是，义与利的结合，必须以义为前提。“不 义而富且贵, 于我如浮云。” 孔子的这句话, 在几千年中影响深远。他们悟遵 “儒道”, 在 经商中 “非义弗取”。商人经商, 不仅取之有 “道”, 同时还要取之有 “度”。这样, 生意 自会兴隆, 财源必然茂盛。儒家学说, 本是 用于 “齐家治国平天下” 的理论, 他们则用 之于经商, 其 “灵验”也颇为明显。

\section{2 以布衣结交天子, 寻求政治庇护, 保护其 经济利益}

江春深谙官商结合能发大财的道理, 于 是他在经商过程中始终不忘和官府搞好关 系，并且以大投资来换取其在政治上的权力。 因其勤于经营，又 “练达明敏，熟悉盐法”, 颇得当地监管盐业的官员器重, 也得盐商们 爱戴, 遂被推为总商。一朝有权在手，他便 大加施展经商才略, 一时间成为扬州商界举 足轻重的人物, 《撮县志》中称其: “才略雄 骏, 举重若轻, 四十余年, 规划深远。”

乾隆皇帝在位时曾 6 次南巡扬州, 就曾 居住在江春的康山草堂之中, 还游其园林, 留有诗作和题字。江春也乘机鞍前马后, 扫 除宿戒, 为皇帝和朝廷服务, 深得乾隆好感。

在江春的经商生涯中, 他不仅遇上乾隆 6 次南巡, 还有清廷数次对边疆用兵, 庆祝 皇太后万寿节典礼, 以及许多大工程和大灾 的赈济等, 每次的费用支出都很浩繁, 但他 为筹措经费尽心尽力, 出谋策划条条是道, 很得朝廷和地方政府的信赖。由此亦可见江 春之财资和影响力。反过来, 乾隆也会给江 春不少好处, 除给江家园林赐名题诗外, 还 赐金玉器玩, 御书 “怡性堂” 额, 加授布政 使、奉震苑卿等衔, 荐官至一品, 后并赏借 
白银 55 万两, 老年时, 乾隆还准其进京赴皇 家 “千叟宴”, 待遇和官职可谓居扬州盐商之 冠。

盐商江春之所以要结交天子, 寻求政治 庇护, 是由于盐业为国家所控制, 为了获取 高额利润, 就会将主要精力放在疏通官方关 系上。在处理这些事上, 江春凭借其杰出的 公关手段, 广交官员, 拉近与官员的距离, 取得官员信任; 攀援权贵, 逢迎皇帝, 换得 政治好处, 获得了巨大的政治利益。他通过 这种途径来谋求政治保护伞, 对成功处理繁 难的盐业事务无疑提供了保障性和便利性。 而官僚则通过这种交往, 获得许多经济上的 实惠。官商互利, 从而使江春乃至能 “领袖 淮纲数十年” ${ }^{[11]}$, 成为官场的 “不倒翁” “常 青树”, 缔造了一段 “以布衣上交天子” 的历 史佳话。

\section{3重视对后代的教育, 实现 “知识管理”}

徽商很注重后代的教育问题, 通过教育 不仅将 “儒” 的思想教与后代, 更是将 “贾” 的经营思想传与后代。

“儒” 的思想在教育上的体现：首先， 徽商注重中国传统典籍的学习, 尤其是对儒 家经典的学习, 久习经典, 自然就会形成超 脱一般商人的气质; 这种凝诚信、仁义、坚 持、儒雅与机敏于一体的气质使得徽商对顾 客会有更好的接纳度。其次, 儒家经典传输 给人的不仅是做人的技巧, 而且更是为学习 者树立做人典范; 这样就使得他们在顺境中, 不会狂妄自大; 在逆境中, 能够自持而不会 放弃。正是因为这两种益处, 才成就了一个 又一个精明而又儒雅的徽商。

“贾” 的思想在教育上的体现：为了将自 己家族积攒下来的经营方法和管理经验传承 下去, 以及提高整个盐业家族的文化素质, 实现可持续发展, 同样也要求徽商对自己后 代的教育。

因此, 徽州盐商特别重视文化教育事业, 他们为了培养封建人才, 不吝巨款投资教育。 江春就是其中之一, 首先, 他在宗族中培养 人才, 以家乡宗族子弟助己或为已所用, 将 后代带入到自己的产业中, 其一可以培养产 业的凝聚力, 实现知识管理; 其二也可以使 后代实现从 “吃苦型” 向 “知识型” 创业者 的转型; 其三, 为了在以后的发展中创造有
利条件, 最好要能与朝廷命官共室议事, 其 客观要求还是要有良好的文化素质。其次, 培养宗族子弟, 从而步入仕途, 进一步培植 其政治势力, 扫除其发展障碍, 保护其商业 利益。

\section{4以文会友，构建广泛的社交网络}

经过儒学和宗族教育陶出来的徽商, 在 社会交往中便比较活跃, 而且文化品位也比 较高。江春就是一位有一定文化素养的盐商, 对于文学艺术也有较高的鉴赏能力和爱好, 他在处理日常盐务活动后, 闲暇时从事诗文 创作, 著有《随月读书楼诗集》三卷、《黄海 游录》一卷, 另有《水南花墅吟稿》等著作。 他以文会友, 提倡和奖励戏曲, 招引戏曲人 才, 组建戏曲家班, 与艺人为友, 江春家有 德音、春台两个戏班, 在招待四面八方官僚 文人和社会名流的酒宴上演出。凡士大夫路 过扬州, 多住宿于江春的康山草堂, 他家中 常常奇士云集, 盛极一时。

江春 “垂范两淮盐业五十年” 的鼎盛时 代, 蓄养了大量文人, 有一文人常年 “馆于 家”, 而江春也未感倦怠。江春对文人的款待 与资助, 使文人得以生存及进行各类的文化 活动, 而江春则在与文人的交往中得到了社 会名声, 礴其社会地位事实上也得到了认 可。

凭借这些公关手段, 他结交了一大批社 会名流，有诗人、画家、戏曲家、词人、思 想家、作家等诸多各界精英, 构建了广泛的 社会网络。其结果就是: 首先, 提升了其个 人文化品位和文学素养; 其次, 为其领导两 淮盐业, 提高在政界、商界、学界的社会影 响力, 发挥了极大作用, 既扩大了社会影响, 也取得了良好的社会效应; ${ }^{[14]}$ 然后, 通过这 种影响力能够引进人才, 吸纳很多能人贤士 到自己的产业中做事, 为自己所用; 最后, 通过江春构建的社会网络, 为文化融合提供 了强大的动力和广阔的平台, 同时也促进了 扬州文化的多样性、多元化发展。

\section{5敢于担当 “社会责任”, 树立良好的社会 形象}

在税收方面, 盐业税收是仅次于田赋的 财政收入, 是封建社会政府财政的主要收入 
之一。 ${ }^{[15]}$ 据《清朝野史大观》卷2记载: “乾 嘉间，扬州盐商豪侈甲天下，百万以下者皆 谓之小石, 彼纲总得嘻笑而呼叱之。” 总商为 大商, 资本当在百万以上。江春是总商, 他家 的盐业资本亦当在百万以上。那么他作为 “纳 税人”, 自然会缴纳很大比例的盐业税收, 这 对清政府来说会是一项不小的国库收支。

在军需赈灾方面, 江春于 1773 年捐款 400 万两银子作为小金川平乱的经费, 1788 年捐 款 200 万两银子作为平定台湾林爽文乱子的 费用。1792年清朝廷进军西藏, 1799年平定 川陕之乱, 江春分别捐款 150 万两、100万两、 200 万两银子。从1748年征讨大小金川, 1795 年镇压湖南石三保苗民起义, 两淮盐商8次捐 款军需银共达 1510 万两。1782年江春捐款 200 万两银子修黄河, 1788 年捐款 100 万两银 子救济水灾难民，1771年捐款恭贺贺皇太后 80 寿诞, 江春等盐商出 20 万两银子作为皇家 费用, 60万两作为贺礼。自康熙至嘉庆年间, 清朝廷收到扬州盐商报效银子达 3982 万 2196 两。

在民生与公共设施方面, 盐商为迎接乾 隆帝南巡, 在天宁寺到平山堂一带, 建成卷 石洞天、西园曲水等24景。江春等盐商捐款 修整扬州街道、治理河道, 修建园林、寺庙, 文庙，建立义仓，储备粮食，防止灾荒。扬 州盐商在大旱、大水之年, 民不聊生之际, 设立粥厂, 让老百姓免费吃饭。从1671年至 1840 年, 盐商在赈灾方面共捐款 23 次, 277.9596 万两银子, 捐大米 22.946 万石。盐 商捐款在疫情爆发的时候向社会赈济医药。 他们资助贫困书生, 建育婴堂, 为节妇烈女 树碑立传, 修桥摆义渡, 方便人们交通, 设 拯救落水人的班子, 冬天给穷人发放棉被棉 衣等。江春等盐商为社会公益事业作出了重 大的贡献。

扬州盐商出资兴建和修缮书院, 如三元 坊安定书院、北桥敬定书院、北门外虹桥书 院、广储门外梅花书院等。他们捐款建设西 门义学等, 作为穷人免费读书的学校, 让失 学的儿童有个学习的机会。

江春在 “乾隆中，每遇灾赈、河工，军 需、百万之费, 指顾立办”。疏浚河道, 修堤 筑坝等基础性建设。两淮地区的徽商为了促 进其盐业生产的发展, 扩大盐的生产和运输,
史籍中屡见不鲜。康熙初, 檁商江演 “以盐 策起家” “浚扬州伍佑东河二百五十里及安丰 串场官河, 盐艘免车运之劳, 商民受益”。 他们浚河筑是, 便利盐船行驶, 这些都是发 展两淮盐业所必须的 “基础工程”，是盐业生 产和运输这两个重要环节中的基本建设。两 淮地区的盐商正是在这样的盐业发展的条件 下进一步繁华起来的。

总之，像江春这样的盐商投资于教育、 文化、卫生、慈善、交通等公益事业，不仅 造福于民众, 推动了地方事业的发展和城市 的繁荣，而且也为保护和弘扬中华民族的优 秀传统文化做出了贡献。

盐商江春积极支持与捐助社会公益事业, 担当社会责任，其行为无疑是对自己的这会 地位及正面形象的宣传, 比如 (1)按照官府的 指令或劝谕进行社会公益和救助活动, 目的 是便于同官府搞好关系，使业务能够更好地 维持和发展下去; (2) 建设民生与公共设施, 为地方做好事, 目的是为了取悦于土著, 更 好地立足于当地社会; (3)建立书院, 资助文 人, 推动文化发展, 目的是为自己做正面的 宣传, 从而可以吸纳更优秀的人才来帮自己 做事; (4)疏浚和维护河道, 目的是为了保障 了其盐船的通行，有利于其商务的运营。他 为盐业的发展建设了大量的 “基础工程”, 为清代社会公益事业做出了不小的贡献。反 过来也为自己树立了良好的口碑，同时还 告诉我们一个致富不忘回报社会的神圣理 念。 ${ }^{[18]}$

\section{4. 江春经营管理经验的启示}

像江春这样的徽州盐商, 因盐而潮起潮 落, 在数百年的兴衰发展过程中可以总结出 他们在经商时的经营管理经验, 从而给现代 管理者以启示。

（1）他们贾而好儒, 商而兼士, 文化素 质较高, 在营商过程中, 由于对行情的识见 较高, “善识低昂, 时取予”, 因而, 常常能 取得成功。

（2）他们以道营商，以义行事，以良好 的商业道德和较高的商业信誉, 在商界站稳 了脚跟, 并且名利双收。

（3）结交天子，寻求政治庇护，保护其 经济利益。 
（4）重视对后代的教育, 实现 “知识管 理”。

（5）以文会友，构建广泛的社交网络, 招贤纳士，网络人才。

（6）敢于担当 “社会责任”，树立良好的 社会形象, 实现可持续发展。

总之, 徽州盐商在明清经济舞台上对促 进商品生产流通密切地区之间联系, 繁荣都 市市镇经济等方面所起过积极作用, 以及为 创造资本主义萌芽的前提作出过贡献, 是值 得现代管理者所学习的。它带给我们的其实 不仅仅是简单的历史事实，更为重要的是今 天我们研究明清时期徽州盐商江春的经营管 理思想，对于在社会主义市场经济体制下发 展地区经济, 搞好商业流通仍有一定的现实 意义。 ${ }^{[19]}$

\section{致谢:}

本文为四川省哲学社会科学重点研究基 地中国盐文化研究中心重点项目《“两淮八大 总商”之首江春管理思想研究》

（YWHZ12-03）的阶段性成果之一。

\section{References:}

[1]Zirun Yang.Huizhou merchants series 2:Huizhou salt merchants of drive[J].shine,2013:33-35.

[2][4][9]Wuji Book4 Jiang chun zhuang.

[3] Gao feng guang lu da fu feng chen yuan qin bu zheng shi jiang gong mu zhi ming.

[5]Xiaoguang Zheng. The business culture of huizhou merchants[J].Enterprise reform and innovation, 2010(2):48-50.

[6]Lingling Cai.The Entrepreneurs' wisdom of Huizhou merchants[J].Talent and Employment,2012:61-62.

[7]Xueping Wang.The discussion of Yang Zhou salt merchants' Confucian jia[J].Salt culture research review SuperS—retrospect and
prospect:The academic symposium on salt industry system reform in China,2009:219-235. [8][15]Zhongzhou Zhu.The discussion of salt merchants in the qing dynasty stories in liang huai[J].Salt Industry History Research,1991:28-36.

[10]Feng Liu.Salt merchants stories of Jiang Chun[J].Chinese small and medium-sized enterprises, 2008:46-48.

[11]Yi Zhao.Ou bei ji[M].Shanghai Chinese Classics Publishing House, 1997.

[12]Liyuan Tang.New hui business philosophy research[D].Shanghai:Fudan University,2010.

[13]Ming Sun.The qing dynasty imperial salt administrative and salt merchants[C].Northeast Normal University,2012.

[14]Fengxiu Chen.The stories of huizhou merchants and their influence upon the construction of a social network[J].Journal of Anqing Teachers College(Social Science Edition),2012,31(4):63-66.

[16]Liangzhi Sang.Quanta salt merchants stories.[OL].

[17]Jian Gao.Huizhou salt merchants during the Ming and qing dynasties and huaibei region[J].Journal of jixi university,2012:121-122.

[18]Haibo Wu.Huaibei salt merchants and the qing dynasty social public welfare undertakings $[\mathrm{J}]$.

Journal of hunan college of engineering(Social Science Edition) ,2008,18(1):57-60.

[19]Haigen Yu.The analysis of huizhou salt merchants in the Ming and qing dynasties culture personality[J].China's social economic history research,1994:20-30. 